\title{
Recognizing and Intervening in Bias Incidents in the Academic Workplace: A Self-Categorization Theory Perspective
}

In higher education, the problem of bias is under increasing scrutiny. Observers have noted the potential for bias incidents to corrode workplace climate, particularly in fields where women and faculty of color are underrepresented (Carnes, Devine, Isaac, Manwell, Ford, ByarsWinston, Fine, \& Sheridan, 2012). Extant research has examined workplace bias incidents and their effect on perceptions of department climate, as well as how implicit biases influence candidate evaluation in recruitment and promotion processes (Maranto \& Griffin, 2011; Settles, Cortina, Buchanan, \& Miner, 2012; Shea, Malone, Young, \& Graham, under review).

How can we confront bias incidents and mitigate their negative impact in the workplace? Recent research has highlighted the potential of bystander intervention as a tool. Bystander intervention research explores how mobilizing bystanders (or witnesses) to respond to bias incidents might reduce bias and improve workplace climate for women and other underrepresented groups (Becker \& Baretto, 2014; Becker, Zawadzki, \& Shields, 2014; Shea, Young, Malone, Graham, \& Banyard, under review; Swim \& Hyers, 2009). Recent experimental work by Levine and colleagues utilized self-categorization theory (SCT) to explain why someone would or would not intervene in situations of bias (Levine, Cassidy, Brazier, \& Reicher, 2002; Levine, Prosser, Evans, \& Reicher, 2005; Levine \& Crowther, 2008; Levine \& Cassidy, 2009; Levine, Cassidy, \& Jentzsch, 2010). SCT examines the social and psychological process individuals undergo in categorizing themselves and others into in-groups and out-groups. Following Levine and colleagues, we posit that this self-categorization process affects an individual's decision of whether or not to intervene to address a bias incident. In this paper, we 
measure the prevalence of bias incidents in a university recipient of an ADVANCE grant, and apply literature on bystander intervention and SCT to determine which faculty members are most likely to witness and subsequently intervene in bias incidents.

\section{Bystander Intervention and Workplace Bias}

Bystander intervention models were developed in social psychology and sociology to explain how community members respond to crimes; these models have been particularly interested in identifying the factors that promote or hinder more general helping behavior. The most well-known model of bystander action is Latane and Darley’s (1970) situational model. Developed to explain why many people do not step in to help when someone is clearly the victim of a crime, the model includes several key steps: noticing that there is a problem, assuming responsibility and doing something, weighing the costs of intervening and assessing one's ability to intervene, and deciding to take some sort of action. The Confronting Prejudice Responses (CPR) model expands on this approach and includes bystanders' assessment of social context, particularly the power of the perpetrators (Ashburn-Nardo, Morris, \& Goodwin, 2008; AshburnNardo, Blanchar, Petersson, Morris, \& Goodwin, 2014). Banyard (2015) further notes the complexity of providing help in difficult interpersonal situations, such as when there is a risk for sexual harassment or assault.

In the workplace, bias incidents involve disparaging comments about, or unequal treatment of, an individual or group based on their group membership (e.g., gender, ability status, sexual orientation, race, ethnicity, national origin, socioeconomic background). Such behaviors may range from subtle incidents of implicit bias to overt displays of discrimination, including verbal criticisms, jokes, unfair treatment, or outright bullying. In the academic workplace, bias incidents have been found to have a significant negative impact on perceptions of workplace 
climate and job satisfaction (Settles et al., 2012). Further, research has found that targeted negative behavior in the workplace affects not only the direct victims of such behavior, but also observers and their job performance and satisfaction (Miner-Rubino \& Cortina, 2004; Nielsen \& Einarsen, 2012), spreading to others and impacting the entire organization (Harvey, Treadway, \& Heames, 2007; Low, Radhakrishnan, Schneider, \& Rounds, 2007; Vartia, 2001).

Although confrontation by victimized employees can be an effective tool to reduce bias (Brinkman, Dean, Simpson, McGinley, \& Rosén, 2015; Shelton \& Stewart, 2004), employees often avoid responding to bias incidents against themselves either because they do not interpret it as such, or because they wish to avoid reprisal and maintain their reputation and status in the workgroup (Ashburn-Nardo et al., 2014; Bowes-Sperry \& O’Leary-Kelly, 2005). This may be especially true in the academic workplace, a setting where bias incidents tend to be ambiguous rather than overt, the atmosphere is charged with the pressure of peer evaluation, and reputation and status are central to faculty members' identity and career success. In this environment, it may be especially important to rely on the intervention of third parties who often witness these acts of bias (Ashburn-Nardo et al., 2014; Ashburn-Nardo et al., 2008; Bowes-Sperry \& O’LearyKelly, 2005). By their presence, these bystanders have the opportunity to take action by discouraging the problematic behavior (e.g., by speaking up to challenge a disparaging comment made in a faculty meeting or on a search committee). Alternatively, they could choose to do nothing or even to encourage problem persistence (Ashburn-Nardo et al., 2008).

Harvey et al. (2007) describe how responses of observers to workplace bullying can be instrumental in mitigating bullying behavior in organizational contexts. By choosing to intervene, bystanders can be allies in creating a climate that works against biases, preventing future bias incidents from occurring and making an organization more welcoming for members 
of underrepresented groups. Bystanders, by their words and actions, have the potential to shift norms and expectations, transforming the very department climates that had facilitated the bullying and bias incidents in the first place.

\section{Self-Categorization Theory (SCT)}

SCT focuses on how individuals organize their social world in terms of in-groups and out-groups (Turner, Hogg, Oaks, Reicher, \& Wetherell, 1987). Groups formed based on sociodemographic criteria such as gender, race, and ethnicity are one form of social group organization (Hogg \& Terry 2000). Unique yet malleable attributes (e.g., attitudes, feelings, behaviors) form prototypes that accentuate the distinction between one group and another (Hogg, 2001). For example, a prototypical attitude for teachers is to promote learning, whereas in contrast the prototypical attitude for a student is to be inquisitive. Prototypical group members are viewed through the lens of how stereotypically they fit the group rather than their personal idiosyncrasies (Hogg, 2001). As in-group members identify more with their in-group and identify less with out-groups, they become depersonalized. Depersonalization is the process by which in-group members perceive themselves in terms of in-group prototypes rather than their personal attributes (Hogg \& Terry, 2000; Hogg, 2001). When bias occurs in the academic workplace, depersonalization could prevent a faculty member from intervening in order to avoid going against a strongly held group cohesion norm (Biggane, Allen, \& Albert, 2016). In this paper, we will draw on SCT to argue that the saliency of in-group and out-group membership (e.g., underrepresented in-group, department in-group) during situations of bias will influence faculty members’ ability to recognize bias incidents and intervene.

Building on SCT, scholars have theorized and tested how a superordinate identity brings about inclusivity between in- and out-groups (Mummendey \& Wenzel, 1999; Wenzel, 
Mummendey, \& Waldzus, 2007). A superordinate identity is composed of attributes that are shared between groups. For example, faculty members can be of different races (i.e., outgroups), yet still share the common superordinate faculty member social identity. The inclusivity of a shared superordinate identity can supplant in- and out-group conflicts between group members. In this process of establishing inclusivity, intergroup members positively evaluate shared social categories between subordinate groups (i.e., in-groups and out-groups) to form a superordinate group (Mummendey \& Wenzel, 1999). Through this process, tenured faculty members (i.e., subordinate identity) and underrepresented group faculty members (i.e., subordinate identity) can perceive a salient and shared superordinate departmental identity. However, untenured faculty may not share this identity, since their probational status may keep the inclusive superordinate departmental identity just out of their reach. Since SCT defines group membership in terms of intergroup comparisons, this process of superordinate group inclusivity involves comparisons to out-groups that may result in discrimination.

While SCT focuses on intergroup comparisons, intersectionality adds a layer of complexity in highlighting the importance of how social status categories (e.g., race, class, gender, sexual orientation, disability) intermingle to create social groups that encounter bias and discrimination because of their membership in multiple social status categories (Acker, 2012; Collins 1998; Crenshaw, 1991). For example, racism and sexism cannot be discussed as mutually exclusive forms of discrimination, but rather as simultaneous forms of disempowerment for nonwhite women (Collins, 1998). Much like SCT, these intersections of social group categories (e.g., gender, race) can influence how individuals perceive and experience forms of oppression (Shields, 2008), such as gender bias and intervening in bias situations. More recently, scholars (Acker, 2012; Hart 2016; Lester, Sallee, \& Hart, 2017) have explored an intersectional critique 
of inequality, examining gendered, racial, and class assumptions within the organizational context. In this paper the social group membership (e.g., gender, race, tenure status) of individuals will have important implications for identification with in- and out-group social categories, and how this affects witnessing and intervening in bias situations.

\section{ADVANCE IT}

This study was conducted at a university that received an ADVANCE Institutional Transformation (IT) award in 2012, and subsequently launched a series of initiatives to improve the representation of women faculty in STEM disciplines as part of its larger goal of institutional transformation. From its inception, ADVANCE programming stressed that institutional transformation in a university is possible only with the involvement of large numbers of faculty in designing and implementing change. In keeping with this strategy, ADVANCE IT recruited faculty from both STEM and non-STEM disciplines to develop workshops that would raise awareness about implicit bias, equity, and diversity. Based on SCT, such trainings have the potential to enhance the salience of underrepresented social group categories during moments of bias (Hogg \& Terry, 2001). Bystander workshops that help faculty to identify bias could also create opportunities for intervention to confront bias, and thus extend the inclusivity of groups.

\section{Hypotheses}

In this section, we use models of bystander intervention (Latane \& Darley, 1970; Ashburn-Nardo et al., 2008) and self-categorization theory (Turner et al., 1987) to generate hypotheses about bystander intervention in academic workplace bias incidents. These hypotheses address who is likely to recognize and report having witnessed workplace bias incidents, as well as the effects of individual differences, modeling behavior, and contextual variables on who is likely to intervene. 


\section{Witnessing the Bias Incident}

Before people can intervene in a bias incident, of course they must first recognize that a bias incident has occurred in the first place (Latane \& Darley, 1970). Bias incidents can be subtle in nature and can go unnoticed by people who are present. Research suggests that people whose characteristics are similar to those of the targets of unwanted comments or treatment are more likely to recognize bias behavior (Ashburn-Nardo et al., 2008). Based on SCT, a minority ingroup status bystander is more likely to witness bias when the target of bias is also of minority status. Since women are targets of discrimination more often than men (Schmidt, Branscombe, Kobrynowicz, \& Owen, 2002), women are more likely to recognize subtle forms of bias of which their male colleagues are often unaware (Basford, Offermann, \& Behrend, 2014; Inman \& Baron, 1996; Rotundo, Nguyen, \& Sackett, 2001). Following this line of reasoning, members of groups underrepresented based on their gender, race/ethnicity, and/or sexual orientation, or the intersection of two or more minoritized group memberships, are more likely to recognize subtle racist or biased behavior. Therefore, we hypothesize as follows:

Hypothesis 1: Faculty who are members of one or more groups that are underrepresented based on their gender (Hypothesis 1a), race/ethnicity (Hypothesis 1b), or sexual orientation (Hypothesis 1c) will be more likely to report having witnessed bias incidents.

Bystander training to promote awareness and helpful actions has become a promising practice for addressing problems ranging from school bullying to sexual assault and intimate partner violence (Banyard, 2011; Banyard, 2015; Jackson, Hillard, \& Schneider, 2014). Such workshops have demonstrated effectiveness in helping employees recognize forms of implicit bias, discrimination, and harassment that might have otherwise gone unnoticed, including sexual 
harassment within the military (Buchanan, Settles, Hall, \& O’Connor, 2014) and the federal government (Antecol \& Cobb-Clark, 2003).

Based on SCT, the training may help by manipulating what social categories become situationally salient (Hogg \& Terry, 2001), making victims of bias a salient and thus a visible group in situations of bias. This is supported by Levine et al. (2005, p. 451) whose experimental studies have demonstrated that the salience of "intergroup rivalries” can be shifted towards “more inclusive or common categorization” (see also: Levine et al., 2002; Levine \& Crowther, 2008; Levine \& Cassidy, 2009; Levine et al., 2010.) Their findings show that when the salience of group membership shifts from subordinate to superordinate social categorization, “[p]revious inter-group rivalries become submerged within a more inclusive or common categorization. Those who were previously identified as out-group members are now extended the benefits of group membership” (Levin et al., 2005, p. 451). Using this rationale, faculty members who do not share a subordinate identity (e.g., gender, race/ethnicity) can be influenced into extending group membership and its attendant benefits to victims of bias through training. Thus, we hypothesize as follows:

Hypothesis 2: Faculty who have participated in workshops and activities about the nature and effect of bias will be more likely to report having witnessed bias incidents.

\section{Bias Awareness and Social Identity as Precursors to Intervening}

In Hypothesis 1, we propose that individuals from underrepresented groups based on gender, ethnicity/race, and sexual orientation are more likely to witness or to recognize bias incidents due to a salient in-group identity. Prior research has found that underrepresented group members, such as women, are more likely to recognize bias incidents as a problem, assume responsibility, and decide to act (Ashburn-Nardo et al., 2008). Since one must be able to identify 
a bias incident before interpreting the incident as a problem and taking action to intervene, it follows that members of one or more of these underrepresented groups should be more likely to assume responsibility and intervene. We therefore hypothesize that:

Hypothesis 3: Faculty who are members of one or more groups that are underrepresented based on their gender (Hypothesis 3a), race/ethnicity (Hypothesis 3b), or sexual orientation (Hypothesis 3c) will be more likely to intervene in bias incidents.

Levine et al. (2005) argue that Latane and Darley’s (1970) bystander effect model is limited in that it only accounts for the numerical presence of others in situations of bias. They point out that according to SCT, what explains perception and action is the social contextual salience of a particular shared social identity (Levine et al., 2005). In essence, not only the number of individuals present but also the "common social category membership between bystander and victim will lead to increased likelihood of intervention in emergency situations” (Levine et al., 2005, p. 445).

Further, individuals who perceive a strong fit between their self and the organizations to which they belong experience depersonalization (Hogg, 2001). In this view, individuals consider themselves members of the organizational in-group and interpret situations in ways that facilitate positive attitudes about their in-group members, influencing the way they behave. Since bias incidents are more likely to involve in-group members acting against out-group members, this dynamic suggests that individuals who perceive themselves as well integrated (i.e., depersonalized) into important informal networks may be more likely to ignore bias incidents or interpret them in a more positive light and be less likely to intervene. Highly depersonalized individuals engage in positive illusions (Biggane et al., 2016), positively distorting work experiences to promote stable relationships. In this manner, the more individuals closely identify 
with and fit within their workplace unit, the more likely they are to put a positive spin on bias incidents to avoid creating instability within the group. Thus, we hypothesize as follows:

Hypothesis 4: The more faculty report that they fit within their department, the less likely they will be to intervene as a bystander after having witnessed a bias incident.

In their experiments on bystander intervention, Levine and Crowther (2008) use SCT to explain that groups of men are less likely to help female victims of male aggression because of the gender out-group status of the women in these situations. In an academic setting, women are more underrepresented in certain disciplines than in others. While it is those very disciplines in which women are underrepresented that more bias incidents occur, it may also be in those disciplines that members are less likely to intervene. This could be because of department cultures that implicitly ignore or support bias incidents or because most department faculty are men who may be less likely to recognize bias incidents because they are not members of the underrepresented group (Ashburn-Nardo et al., 2008; Basford et al., 2014; Rotundo et al., 2001). We therefore hypothesize as follows:

Hypothesis 5: Faculty in colleges where women are underrepresented will be less likely to intervene as a bystander having witnessed a bias incident.

\section{Assuming Responsibility and Weighing the Costs}

Even if a bystander decides that a bias incident is a problem, he or she must assume a sense of responsibility in deciding whether to intervene, and weigh the costs of doing so (Ashburn-Nardo et al., 2014; Eliezer \& Major, 2011; Good, Moss-Racusin, \& Sanchez, 2012). One factor that may reduce a bystander's sense of responsibility or ability to act relates to their position in the organization relative to the perpetrator and to the object of bias. Due to power dynamics, perpetrators of bias often target those of lower or similar rank (Lee \& Brotheridge, 
2011; Ashburn-Nardo et al., 2014), and research shows that individuals feel less responsibility to confront perpetrators of discriminatory behavior when the perpetrator outranks them. In such cases, witnesses are more likely to side with the perpetrator (Samnani, 2013) and therefore not intervene. Lower-ranking individuals are also more likely to feel that intervening is the responsibility of a supervisor or senior employee (see discussion of "social appropriateness of intervention” in Bowes-Sperry \& O’Leary-Kelly, 2005). This is particularly an issue in workplaces or organizational contexts that are hierarchical in structure and where power is highly centralized. When the perpetrator is a peer or a subordinate, workers feel a greater sense of responsibility to confront and perceive fewer costs associated with intervening than when the perpetrator holds a higher position of authority (Ashburn-Nardo et al., 2014).

Untenured faculty and faculty who are not on the tenure track face an especially acute job security risk. These faculty are often at the mercy of tenured faculty who are usually involved in decisions about whether or not to promote tenure track faculty or renew the appointments of nontenure track faculty. Based on SCT (Mummendey \& Wenzel, 1999), in this study we conceptualize untenured and non-tenured faculty as subordinate group members lacking a superordinate (and therefore inclusive) identity within the academic social context. This excluded position will make non-tenured faculty feel less responsibility to intervene (AshburnNardo et al., 2014) in situations of bias. Therefore, we extend this relationship between rank and intervening to the academic environment by hypothesizing as follows:

Hypothesis 6: Faculty who are tenured (i.e., associate and full professors) will be more likely to intervene during bias incidents than non-tenured faculty (i.e., assistant professors) and faculty not on the tenure track. 
The sense of responsibility to intervene can diminish if bystanders think that other colleagues will step in (Bickman, 1972; Latane \& Darley, 1968). Latane and Darley (1968) highlighted how bystander inaction is more likely in the presence of a greater number of other individuals, as the sense of responsibility is diffused. In such instances, bystanders may think that others should take the lead in addressing the incident, or they may assume that others have already done so. In line with this reasoning, we hypothesize that:

Hypothesis 7: Faculty who report a higher likelihood of colleagues intervening in bias incidents are less likely to intervene after witnessing a bias incident.

\section{Method}

\section{Procedure and Participants}

An annual workplace climate survey was administered using Qualtrics to 1,055 tenure track and non-tenure track faculty at a medium size public university in the northeast United States. In addition to demographic and work-related indicators, the survey included questions about whether faculty had witnessed bias incidents and engaged in or witnessed colleague bystander intervention. Faculty members were sent three email reminders, once per week during the last three weeks of the survey, to complete the survey. Three hundred and ninety-four (394) faculty completed the climate survey (a response rate of approximately 37\%). Respondents were assured anonymity, confidentiality, and that their results would only be reported in aggregated form to ensure that individual respondents could not be identified. This was achieved by reporting analyses by demographic groups of 10 or more members. As an incentive for completing the survey, respondents had the option to provide an email address on a separate survey to enter a drawing for a \$1,000 research/development grant. 
Prior to answering questions on workplace bias and intervention, respondents answered a series of questions regarding their opinion of factors concerning the distribution of workplace duties including teaching and advising, as well as the types of scholarly activities they conduct. Questions on bias and intervention fell roughly in the middle of the survey. Missing data on “witnessing bias” and key demographics (i.e., gender, race/ethnicity, and sexual orientation) reduced the number of useable surveys from 394 to 344. Our first empirical analysis aimed to identify who witnesses bias incidents, and it relies upon the full sample of respondents. In our second empirical analysis, we were interested in determining who would intervene in bias incidents after witnessing them. To this end, we created a subsample of respondents who had witnessed the bias incident. Respondents who reported not having witnessed bias incidents were excluded from this portion of the analysis examining bystander intervention, since witnessing bias is a necessary condition of intervention. The sample size of faculty who reported having witnessed one or more bias incidents was 214, reduced to 195 after accounting for missing data, or about $54 \%$ of survey respondents.

\section{Measures}

Underrepresented Group Membership. Underrepresented group membership was measured using a series of dichotomous variables for gender, race/ethnicity, and sexual orientation. Specifically, we included three sets of dummy variables, one for each of the following: gender (where woman $=1$ and $0=$ man); race/ethnicity (where $1=$ Hispanic, Black, Asian, or Other; and 0 = non-Hispanic white); and LGBQ+ (where 1 = bisexual, gay, lesbian, questioning, or other; and $0=$ heterosexual). No respondents were missing data on our gender variable, but $10.9 \%$ did not provide data on their race/ethnicity, and $11.2 \%$ did not report sexual orientation. These levels of missing data were not enough to warrant that we exclude these 
measures, only that we interpreted the findings regarding race/ethnicity and LGBQ+ status cautiously.

Workplace Bias Training. A dummy variable was used to indicate whether respondents reported participating in any workshops related to implicit bias offered at the university. These workshops, held at least once per academic year, focus on identifying bias in the faculty search process. Department chairs and search committee chairs encouraged faculty to attend, and all faculty search committee members were sent an invitation via email. Participation was voluntary, and most faculty who attend do so only once. Workshop participants observe (and afterwards, discuss) an interactive theatre presentation on implicit bias and micro aggressions that might arise during various stages of the search process (including during the review of applications and discussion of applicants). While it is possible that the topic of intervening could arise casually during workshop discussions, the focus of the workshop was primarily on how to recognize bias incidents. In the 2015 survey, 81 (21\% of our sample) respondents reported participating in at least one of these workshops compared to a total of 140 at the university.

Witnessing Bias Incidents. We measured “witnessing bias incidents” using three items adapted from measures of bystander behavior in interpersonal violence reworded to reflect workplace bias incidents (Banyard, Moynihan, Cares, \& Warner, 2014; Brown, Banyard, \& Moyniham, 2014; McMahon, Palmer, Banyard, Murphy, \& Gidycz, 2015). The text for these three items as well as their respective factor loadings are presented in Table 1 . The response scale of each item ranged from 0 (never witnessed) to 3 (witnessed often/more than 5 times). Results of a principal component factor analysis with varimax rotation indicated one factor (see Table 1) that explained $64.1 \%$ of the variance in these items (with an Eigenvalue of 1.92). Reliability analysis of these items yielded a Cronbach’s alpha of .71, exceeding the threshold 
established by Nunnally (1978). We used the sum of these three items to create an ordinal witnessing "score" that ranged from 0 to 9.

Table 1

Results from Principal Components Factor Analyses for Witnessing Bias,

Intervening, Colleague Intervention, and Department Fit*

Constructs and Items

Loadings

Witnessing Bias (Eigenvalue: 1.92)

How often in the past year have you:

1. Heard faculty make insensitive or disparaging comments about someone because of their gender, disability status, sexual orientation, or race/ethnicity?

2. Had the chance to support someone who raised issues about the unequal treatment of underrepresented minorities (based on gender, disability status, sexual orientation, or race/ethnicity)?

3. Heard a co-worker seem to imply that underrepresented minorities (based on gender, disability status, sexual orientation, or race/ethnicity) are not as strong in their field?

Intervention (Eigenvalue: 2.19)

How often in the past year have you said or done something:

1. When you heard faculty make insensitive or disparaging comments about someone because of their gender, disability status, sexual orientation, or race/ethnicity?

2. When you had the chance to support someone who raised issues about the unequal treatment of underrepresented minorities (based on gender, disability status, sexual orientation, or race/ethnicity)?

3. When you heard a co-worker seem to imply that underrepresented minorities (based on gender, disability status, sexual orientation, or race/ethnicity) are not as strong in their field?

Colleague Intervention (Eigenvalue: 2.59) 
How likely would your department colleagues be to say or do something:

1. If they heard insensitive or disparaging comments about someone because of their gender, disability status, sexual orientation, or race/ethnicity?

2. To support someone who raised issues about the treatment of underrepresented minorities (based on gender, disability status, sexual orientation, and race/ethnicity)?

3. If they heard a co-worker seem to imply that underrepresented minorities (based on gender, disability status, sexual orientation, or race/ethnicity) are not as professionally capable in their field?

Department Fit (Eigenvalue: 3.23)

Indicate your level of agreement with each of the following statements:

1. Attempts to make things better around here will not produce much real change

2. I feel excluded from informal networks in my department

3. It is safe to take a risk in this department

4. People in this department deliberately act to undermine my work

5. I received enough feedback on my progress toward tenure/promotion

6. I feel like I 'fit' in my department

Bystander Intervention. Respondents who reported having witnessed bias incidents were asked how often they had engaged in bystander intervention behaviors. To gauge their intervention, they were provided a response range from 0 (never intervened) to 3 (intervened often/more than five times). Principal components factor analysis with varimax rotation yielded one factor (see Table 1). Reliability analysis yielded a Cronbach’s alpha of .81, above the 
traditional cutoff of .70 . We used the sum of these three items to create an ordinal intervention score that ranged from 0 to 9. A third of those who witnessed at least one bias incident (and are therefore included in this portion of the analysis) reported never intervening, while $70 \%$ said they intervened at least once.

Colleague Intervention. We then turned to assess respondents’ perceptions that their colleagues would intervene in bias incidents. We measured respondents’ perceptions of colleague intervention on a similar scale, asking respondents to indicate how likely their colleagues would be to intervene if they witnessed bias incidents in the workplace on a response scale ranging from 1 (very unlikely) to 4 (very likely). Factor analysis results (see Table 1) indicated that all three items loaded on a single factor that explained $73.3 \%$ of the variance among these items (with an Eigenvalue of 2.59). Reliability analysis yielded a Cronbach's alpha of 0.92 . We used the sum of the means of the three items to calculate this colleague intervention score.

Department Fit. We measured perceived department fit based on the work of August and Waltman (2004) and other ADVANCE Program faculty surveys (see the Virginia Institute of Technology ADVANCE Portal). Our measure included six questions related to the extent to which respondents felt that they belonged within their departments and among their peers (see Table 1). Respondents rated their agreement on a scale from 1 (strong disagree) to 4 (strongly agree) with six aspects of their work environment. Items 1, 2, and 4 were reverse coded. Results from a principal components analysis suggested that six of these items loaded on one factor with an Eigenvalue of 3.23 (explaining $53.77 \%$ of the variance). Reliability analysis yielded a Cronbach’s alpha of .83. Department fit was calculated using the sum of the means of these six items. 
Rank. We included a series of dummy variables in our intervention models to measure faculty rank. Specifically, we included dichotomous variables for assistant, associate, and full professor. Non-tenure track (e.g., clinical and research faculty and full time lecturers) is the reference group, given that this group lacks many of the workplace protections associated with tenure, including not only job security but also the opportunity to serve on various committees, hold various leadership roles in the department and university, and vote on many key decisions.

College where women are underrepresented. We included a dummy variable to indicate whether respondents' primary college is one in which women are underrepresented, that is, where they comprise less than the $45 \%$ of women faculty representation overall at the institution. We established this benchmark of $45 \%$ because this was the overall percentage of women faculty employed at the institution as a whole. A value of 1 indicates that the respondent belonged to a college where women are underrepresented, while a value of 0 designates respondents who belonged to a college where women are not underrepresented. With this measure, we identified colleges that have lower levels of women's representation than in the institution as a whole. Colleges in which women were underrepresented in 2015 include the College of Business (35.1\% women); the College of Engineering and Physical Sciences (25.0\% women); the Earth, Oceans and Space Institute (18.6\% women); the College of Life Science and Agriculture (37.8\% women); and the university’s branch campus (34.1\% women). Women were not underrepresented relative to their representation in the university as a whole in the Library (82.4\% women), the College of Health and Human Services (68.0\% women), the College of Liberal Arts (55.1\% women), and the Law School (46.4\% women). 


\section{Data Analysis}

Descriptive statistics for the categorical variables are reported in Table 2 . The sample was relatively evenly split among men (46.7\%) and women (53.3\%); 7.6\% of respondents were members of underrepresented race/ethnicity groups, and 6.9\% reported a sexual orientation other than heterosexual (i.e., LGBQ+). With respect to rank, $66.3 \%$ of respondents were tenure track faculty (i.e., 13.5\% assistant professors, 27.4\% associate professors, and 25.4\% full professors) and $33.7 \%$ were non-tenure track faculty. Forty-four percent (43.7\%) of respondents were from colleges where women are underrepresented when compared with their average representation at the university. Twenty-one percent (20.6\%) of respondents had participated in at least one bias awareness workshop.

Table 2

Descriptive Statistics for Categorical Variables

\begin{tabular}{|c|c|c|c|}
\hline Variable & Group & $\begin{array}{c}\text { n (\% based on } \\
394 \text { sample } \\
\text { size) }\end{array}$ & $\begin{array}{l}\mathrm{N} \text { (\% based on } \\
1055 \text { faculty } \\
\text { population) }\end{array}$ \\
\hline \multirow[t]{2}{*}{ Gender } & Men & $184(46.7 \%)$ & $575(54.5 \%)$ \\
\hline & Women & $210(53.3 \%)$ & $480(45.5 \%)$ \\
\hline \multirow[t]{3}{*}{ Race/ethnicity } & White & $321(81.5 \%)$ & $802(76.0 \%)$ \\
\hline & Black, Hispanic, Asian, Other & $30(7.6 \%)$ & 119 (11.3\%) \\
\hline & Missing/unreported & $43(10.9 \%)$ & 134 (12.7\%) \\
\hline \multirow[t]{2}{*}{ Sexual Orientation } & Heterosexual & $323(82.0 \%)$ & Unreported \\
\hline & LGBQ+ & $27(6.9 \%)$ & Unreported \\
\hline $\begin{array}{l}\text { Attended at least one } \\
\text { Implicit Bias-Training }\end{array}$ & Attended None & $313(79.4 \%)$ & 915 (86.7\%) \\
\hline Workshop & Attended at least one & $81(20.6 \%)$ & $140(13.3 \%)$ \\
\hline
\end{tabular}


Rank/Tenure

Representation of
Women In Respondent's College
Non-Tenure Track Faculty

Assistant Professor

Associate Professor

Full Professor

Women Represented At or

Above Institutional Average

Women Underrepresented
$133(33.7 \%) \quad 410(38.9 \%)$

$53(13.5 \%) \quad 133(12.6 \%)$

$108(27.4 \%) \quad 258(24.4 \%)$

$100(25.4 \%) \quad 254(24.1 \%)$

215 (46.3\%) 553(52.4\%)

$172(43.7 \%) \quad 502(47.6 \%)$

We examined the bivariate relationships between each of our independent variables and the dependent variables of witnessing bias and bystander intervention. Bivariate correlations between all variables in this study are reported in Table 3. We used t-tests of differences in means to test for group differences in witnessing bias and intervening in bias incidents. We then used multiple logistic regression models to test our hypotheses in multivariate models. 
Table 3

Correlation Matrix

\begin{tabular}{|c|c|c|c|c|c|c|c|c|c|c|c|c|c|}
\hline & 1 & 2 & 3 & 4 & 5 & 6 & 7 & 8 & 9 & 10 & 11 & 12 & 13 \\
\hline 1. Female & 1 & & & & & & & & & & & & \\
\hline 2. Faculty of Color & n.s. & 1 & & & & & & & & & & & \\
\hline 3. $\mathrm{LGBQ}^{+}$ & n.s. & n.s. & 1 & & & & & & & & & & \\
\hline $\begin{array}{l}\text { 4. Attended at least one } \\
\text { Implicit Bias-Training } \\
\text { Workshop }\end{array}$ & n.s. & n.s. & n.s. & 1 & & & & & & & & & \\
\hline $\begin{array}{l}\text { 5. Non-Tenure Track } \\
\text { Faculty }\end{array}$ & 0.129 & -0.177 & n.s. & -0.265 & 1 & & & & & & & & \\
\hline 6. Assistant Professor & n.s. & 0.254 & n.s. & n.s. & -0.278 & 1 & & & & & & & \\
\hline 7. Associate Professor & n.s. & n.s. & n.s. & 0.138 & -0.433 & -0.242 & 1 & & & & & & \\
\hline 8. Full Professor & -0.214 & n.s. & n.s. & 0.18 & -0.408 & -0.23 & -0.358 & 1 & & & & & \\
\hline $\begin{array}{l}\text { 9. College where } \\
\text { women under- } \\
\text { represented }\end{array}$ & -0.236 & n.s. & n.s. & 0.141 & n.s. & 0.113 & n.s. & n.s. & 1 & & & & \\
\hline 10. Witnessing Bias & 0.198 & 0.187 & 0.115 & n.s. & -0.22 & n.s. & 0.115 & 0.12 & -0.131 & 1 & & & \\
\hline 11. Intervention & 0.257 & 0.286 & n.s. & n.s. & -0.151 & n.s. & n.s. & n.s. & -0.206 & 0.713 & 1 & & \\
\hline $\begin{array}{l}\text { 12. Colleague } \\
\text { Intervention }\end{array}$ & n.s. & n.s. & n.s. & n.s. & n.s. & n.s. & n.s. & n.s. & -0.15 & -0.268 & -0.216 & 1 & \\
\hline 13. Department Fit & -0.201 & n.s. & -0.15 & 0.135 & n.s. & n.s. & n.s. & n.s. & n.s. & -0.24 & -0.271 & 0.36 & 1 \\
\hline
\end{tabular}


Running head: BIAS INCIDENTS IN THE ACADEMIC WORKPLACE

22

We estimated models for witnessing bias incidents using the entire sample of faculty ( $\mathrm{n}=$ 344); the second and third models include only those respondents who reported having witnessed bias incidents $(n=195)$ since this is a prerequisite for bystander intervention. We tested for statistical significance of the regression relationships using the Wald statistic (which tests the null hypothesis that a given variable’s estimated coefficient is zero) and p values. For model fit, we used the Likelihood Ratio Chi-Square (which, in ordinal regression, tests the model against the null hypothesis that all predictors are equal to zero). The results are reported below.

\section{Results}

Hypotheses 1a, 1b, and 1c were supported by the results of our analysis. While $54 \%$ of faculty reported having witnessed one or more of three forms of bias incidents, independent sample t-tests reveal that the average number of bias incidents witnessed is higher among: women respondents compared to men $(\mathrm{M}=1.71$ and 1.02, respectively; $\mathrm{t}=-3.88 ; \mathrm{p}<.001)$, members of underrepresented race/ethnicity groups compared to non-Hispanic white faculty (M $=2.48$ and 1.28 , respectively; $\mathrm{t}=-3.55 ; \mathrm{p}<.001)$, and members of LGBQ+ groups compared to heterosexual faculty $(\mathrm{M}=2.11$ and 1.35, respectively; $\mathrm{t}=-2.15 ; \mathrm{p}<.05)$ (see Table 4). Small subgroup sample sizes prohibited the creation of the interaction terms needed to examine intersectional groups based on combinations of gender, race/ethnicity, and sexual orientation. Small group sizes also suggests caution when generalizing the results with respect to race/ethnicity and sexual orientation. Despite this limitation, results are consistent with what we would expect given previous research on these underrepresented groups. 
Table 4

Average Witness Score by Gender, Race/Ethnicity, Sexual

Orientation, and Bias Awareness Training Participation

\begin{tabular}{|c|c|c|c|c|c|}
\hline Variable & Condition & $\mathrm{n}$ & Mean & SD & $\mathrm{t}$ \\
\hline \multirow[t]{3}{*}{ Gender } & Men & 175 & 1.02 & 1.21 & \multirow{3}{*}{$-3.88 * * *$} \\
\hline & & & & & \\
\hline & Women & 195 & 1.71 & 2.08 & \\
\hline \multirow[t]{2}{*}{ Race/Ethnicity } & White & 320 & 1.28 & 1.64 & \multirow{2}{*}{$-3.55 * * *$} \\
\hline & Black, Hispanic, Asian, Other & 29 & 2.48 & 2.64 & \\
\hline \multirow{3}{*}{$\begin{array}{l}\text { Sexual } \\
\text { Orientation }\end{array}$} & Heterosexual & 321 & 1.35 & 1.75 & \multirow{3}{*}{$-2.15 *$} \\
\hline & & & & & \\
\hline & LGBQ+ & 27 & 2.11 & 1.99 & \\
\hline \multirow{2}{*}{$\begin{array}{l}\text { Bias Awareness } \\
\text { Training }\end{array}$} & Attended None & 287 & 1.31 & 1.79 & \multirow{2}{*}{-1.46} \\
\hline & Attended at least one & 80 & 1.64 & 1.61 & \\
\hline
\end{tabular}

${ }^{*} \mathrm{p}<.05 ; * * \mathrm{p}<.01 ; * * * \mathrm{p}<.001 ;$ two-tailed t-tests

We tested Hypothesis 2 using both bivariate analysis (see Table 4) and multivariate analyses (see Table 5). Bivariate analysis results did not reveal a significant difference between respondents who reported having attended bias awareness workshops and those who had not. However, Hypothesis 2 was supported in multivariate analysis that controlled for other theoretically important variables (i.e., gender, race/ethnicity, and sexual orientation). First, the results in Table 5 confirm the significant effect of these variables on witnessing bias (Hypothesis 1). That is, women, non-white faculty, and LGBQ+ faculty reported witnessing significantly more bias incidents than their counterparts. Further, the ordinal regression model also finds support for Hypothesis 2, as faculty who attended bias trainings reported witnessing bias more often compared to those who did not attend such trainings. Once we control for gender, 
race/ethnicity, and sexual orientation, bias training was significant and positive (coefficient $=$ 0.55; Wald test $=5.53 ; \mathrm{p}<.05)$.

Table 5

Results from Multiple Logistic Regression of Witnessing Bias

$$
(n=344)
$$

\begin{tabular}{lccc}
\hline & Coefficient & Std. Error & Wald \\
Gender & $0.58^{* *}$ & 0.20 & 8.34 \\
Race/Ethnicity & $0.99 * *$ & 0.35 & 8.17 \\
LGBQ+ & $0.80^{*}$ & 0.36 & 4.94 \\
Bias Training & $0.55^{*}$ & 0.24 & 5.53 \\
& & & \\
\hline Nagelkerke Pseudo $\mathrm{R}^{2}$ & & 0.07 & \\
Likelihood Ratio $\chi^{2}$ & & $23.86 * * *$ & \\
& & & \\
\hline$* \mathrm{p}<.05 ; * * \mathrm{p}<.01 ; * * * \mathrm{p}<.001$ &
\end{tabular}

To test Hypotheses 3a, 3b and 3c, we used the subset of respondents who reported having witnessed at least one form of bias $(n=195)$. (Those who reported not having witnessed bias are not considered bystanders and excluded from subsequent analysis.) The results in Table 6 supported Hypotheses 3a and 3b. That is, women reported having intervened more frequently than men $(\mathrm{M}=2.53$ and 1.44 , respectively; $\mathrm{t}=-3.86 ; \mathrm{p}<.001)$, and faculty who are members of underrepresented race/ethnicity groups reported having intervened more frequently than nonHispanic, white faculty members $(\mathrm{M}=4.00$ and 1.91 , respectively; $\mathrm{t}=-4.18 ; \mathrm{p}<.001)$. However, LGBQ+ faculty were not more likely to intervene than heterosexual faculty (Hypothesis 3c). We conducted a second multiple logistic regression analysis to determine how 
the above predictors of bias intervention operate net of one another (see Table 7). These results showed that gender (Hypothesis 3a) and race/ethnicity (Hypothesis 3b) retain their significant effect on bias intervention even after introducing rank/tenure, in-group status, colleague intervention, and women's underrepresentation into the model (coefficient $=0.72$, Wald $=6.36$, $\mathrm{p}<.05$ for gender; and coefficient $=1.45$, Wald $=9.82, \mathrm{p}<.01$ for race/ethnicity). Sexual orientation (Hypothesis 3c) was not a significant predictor of intervention, just as we found at the bivariate level.

\section{Table 6}

Means and Standard Deviations for Bias Intervention by Gender, Rank/Ethnicity, Sexual Orientation, Rank/Tenure, and Women’s Representation at the College Level

$$
(\mathrm{n}=195)
$$

\begin{tabular}{|c|c|c|c|c|c|}
\hline Variable & Condition & $\mathrm{N}$ & Mean & SD & $\mathrm{t}$ \\
\hline \multirow[t]{2}{*}{ Gender } & Men & 98 & 1.44 & 1.65 & \multirow{2}{*}{$-3.86 * * *$} \\
\hline & & 115 & 253 & 235 & \\
\hline \multirow{4}{*}{ Race/Ethnicity } & & & & & \multirow{4}{*}{$-4.18 * * *$} \\
\hline & White & 178 & 1.91 & 2.04 & \\
\hline & & & & & \\
\hline & Black, Hispanic, Asian, Other & 19 & 4.00 & 2.36 & \\
\hline \multirow[t]{2}{*}{ Sexual Orientation } & Heterosexual & 182 & 2.04 & 2.15 & \multirow{2}{*}{-0.96} \\
\hline & LGBQ+ & 18 & 2.56 & 2.23 & \\
\hline \multirow[t]{5}{*}{ Rank/Tenure } & Non-Tenure Track & 55 & 1.53 & 1.59 & -- \\
\hline & Assistant & 27 & 2.37 & 2.24 & -1.96 \\
\hline & Associate & 63 & 2.33 & 2.13 & $-2.30 *$ \\
\hline & Full & 68 & 2.01 & 2.39 & -1.30 \\
\hline & Not underrepresented & 129 & 2.38 & 2.36 & $3.06^{* *}$ \\
\hline
\end{tabular}




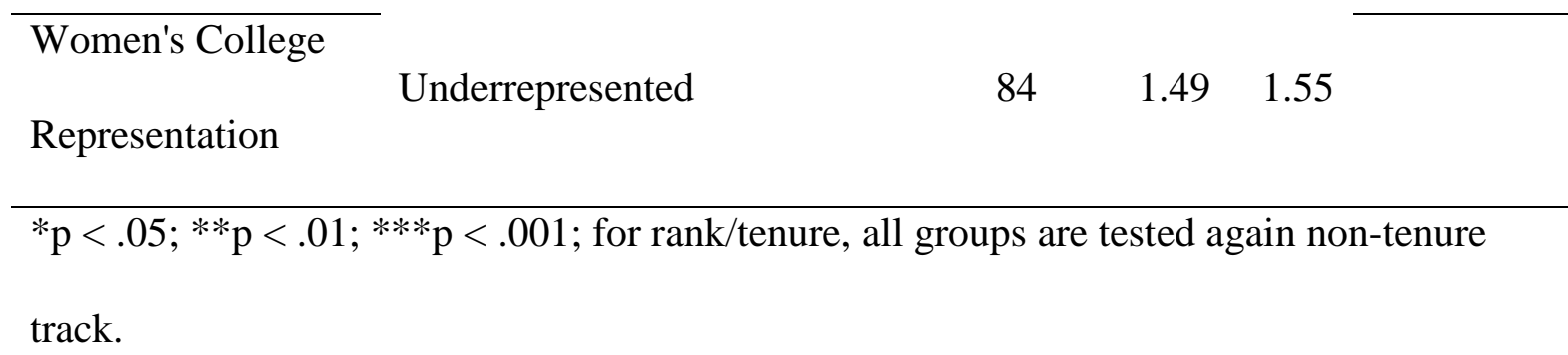

Table 7

Results from Multiple Logistic Regression of Bias Intervention $(n=195)$

\begin{tabular}{|c|c|c|c|}
\hline & Coefficient & Std. Error & Wald \\
\hline Gender & $0.72 *$ & 0.29 & 6.36 \\
\hline Race/Ethnicity & $1.45^{* *}$ & 0.47 & 9.82 \\
\hline $\mathrm{LGBQ}^{+}$ & 0.03 & 0.46 & 0.00 \\
\hline Department Fit & $-0.60 * *$ & 0.23 & 6.80 \\
\hline Assistant Professor & 0.73 & 0.48 & 2.35 \\
\hline Associate Professor & 0.64 & 0.36 & 3.17 \\
\hline Full Professor & $0.94 * *$ & 0.37 & 6.58 \\
\hline Colleague Intervention & $-0.39 *$ & 0.20 & 3.76 \\
\hline Women Underrepresented in College & $-0.73^{*}$ & 0.29 & 6.45 \\
\hline Likelihood Ratio $\chi^{2}$ & & $50.03 * * *$ & \\
\hline Nagelkerke Pseudo $\mathrm{R}^{2}$ & & 0.23 & \\
\hline
\end{tabular}


Consistent with Hypothesis 4, faculty members who reported greater department fit were significantly less likely to intervene (Pearson’s $\mathrm{R}=-0.271, \mathrm{p}<.001$ ). The results in Table 7 indicated further support for Hypothesis 4, as department fit was significant and negatively related to the likelihood of intervening after having witnessed a bias incident (coefficient $=-0.60$, Wald $=6.80, \mathrm{p}<.01)$. Even after we accounted for demographics such as gender, rank, and other predictors of intervening, we continued to find support for our hypothesis that individuals who feel like they "fit” more in their departments are less likely to intervene.

Faculty in colleges where women are underrepresented reported intervening less often compared to faculty in colleges where women are at or above the university-wide level of representation $(\mathrm{M}=2.38$ and 1.49, respectively; $\mathrm{t}=3.06 ; \mathrm{p}<.01)$ (Hypothesis 5) (see Table 6). Our multivariate model also found support for Hypothesis 5; respondents from colleges where women are underrepresented were less likely to intervene after having witnessed one or more bias incidents (coefficient $=-0.73$, Wald $=6.45, \mathrm{p}<.05)$ (see Table 7).

We found mixed support for Hypothesis 6. Associate professors reported intervening significantly more often compared to non-tenure track faculty $(M=2.33$ and 1.53 , respectively; $t$ $=-2.30 ; \mathrm{p}<$.05) (see Table 6). In our multivariate model, we found somewhat more nuanced support for Hypothesis 6 regarding rank and intervening. Specifically, full professors (coefficient $=0.94$, Wald $=6.58, \mathrm{p}<.01$ ) were more likely to intervene in bias incidents compared to nontenured faculty (see Table 7). Our ordinal regression findings therefore provided partial support for Hypothesis 6 - that the likelihood of intervening increases with rank, though only for full professors. The difference between our bivariate and ordinal regression results is likely explained by the fact that women (who are more likely to intervene) are also over-represented among associate professors at this university and in our sample (comprising 59\% of associate 
professors). Controlling for gender altered the results for rank slightly. Taken together, however, our results indicate that even when controlling for other predictors of intervening, rank/tenure is still a significant predictor of bias intervention.

Our results support a significant negative relationship between the perception that colleagues would intervene and bias intervention $(\mathrm{R}=-0.216, \mathrm{p}<.01)$ (Hypothesis 7$)$. The multivariate model results in Table 7 show that the perceived likelihood that colleagues would intervene in bias incidents reduced the likelihood that a faculty member would intervene herself or himself (coefficient $=-.39$, Wald $=3.76, \mathrm{p}<.05)$.

\section{Discussion}

The present study yields some important findings about who witnesses bias in the academic workplace as well as the conditions under which faculty bystanders are more likely to intervene to thwart biased treatment and behavior. That women and other underrepresented groups are more likely to be the targets of workplace bias incidents is well documented (e.g., Basford et al., 2014; Rotundo et al., 2001). Our study demonstrates that even in an academic setting, members of underrepresented groups are better able to recognize bias incidents - a necessary but not sufficient precondition to intervening when bias incidents occur. The same is true for implicit bias training - those who attend such trainings are more likely to report witnessing bias. According to SCT, our findings can be explained due to the salience of underrepresented group targets of bias for both underrepresented group witnesses of bias and attendees of implicit bias trainings.

But upon witnessing bias incidents, who intervenes? We found support for several hypotheses regarding bystander intervention, all of which highlight the complexity of this issue and SCT's value as an explanatory theoretical tool. In line with our predications regarding 
positive illusions and depersonalization, those who report having greater department fit are actually less likely to intervene than those who perceive less department fit. Regarding underrepresented group salience, faculty of color and members of LGBQ+ groups are also more likely to intervene. Further research is needed in this area with respect to intersectionality. For example, Ullrich, Christ, and Schluter (2006) find support for the theory that individuals strongly dual-identifying with a superordinate group (e.g., European) and subordinate group (e.g., German) will perceive a threat to their subordinate group from an outgroup (e.g., people from Eastern European countries) nested within the same superordinate group. Future research on bystander intervention will benefit from these insights, exploring whether tenured faculty who strongly identify with their department or university (i.e., superordinate group) along with their underrepresented group identity (e.g., subordinate race/ethnicity, gender, sexual orientation group) are more likely to intervene (i.e., respond to perpetrator threats) during situations of bias. Identifying the motivation for intervention, either the subordinate group, superordinate group, or combination of two groups, will potentially have important implications for bystander intention trainings, our understanding of academic workplace inclusivity, and self-categorization theory on the whole.

Our results indicate that there is significant variation related to bystander intervention across colleges based on the representation of women faculty in the college. Faculty in colleges and units where women are underrepresented (e.g., business and economics, engineering and physical sciences, life science and agriculture) report lower levels of bystander intervention than those in colleges with a high representation of women. Yet it may be that in those colleges a higher incidence of bias against women occurs. A possible explanation is that as a salient ingroup between women bystanders and women victims, women tend to engage more in bystander 
intervention than men, and therefore, colleges where there are proportionately more women report higher levels of intervention. It may also suggest that those male majority colleges have more male in-group faculty concurrently identifying with the male subordinate group and the superordinate college group, who prefer not to intervene even after having witnessed bias incidents. A third possibility is that faculty in those colleges where there are proportionately more women (e.g., liberal arts and health and human services) have a greater knowledge of bias incidents and ways of intervening. Recently, Hughes, Schilt, Gorman, \& Bratter (2017) find qualitatively a theme that male and female STEM graduate students perceive current numerical parity amongst STEM graduate students to entail future gender equality within the disciplines. The authors point out that such thinking does not address the possibility of a persistent dominant culture of gender inequality within STEM (Hughes et al., 2017). Overall, our results suggest that attempts to increase the representation of women and other underrepresented group members, along with organizational cultural change, might eventually improve their experiences and contribute to a more supportive and fair climate in the fields in which they are currently underrepresented.

Extending theories of workplace intervention to an academic setting and using tenure as a proxy for rank, we find that only full professors are likely to intervene more often on average compared to those without tenure (non-tenure track faculty). In an academic environment, the position of full professor appears to provide a unique measure of job security that, in this case, may free a bias incident witness from the potential cost risk of intervening so that he or she can do the right thing. Extending SCT's (Hogg, 2001) application in the academic workplace, our research suggests that tenured faculty may perform the role of prototypical group members, in that they are more likely to intervene in bias incidents potentially as a form of uncertainty 
reduction. Prototypical leaders make decisions when groups face ambiguous risks and uncertainty (van Knippenberg, van Knippenberg, \& van Dijk, 2000). Furthermore, prototypes as leaders, "impact self-concept of followers and thereby redefine group norms and objectives." (House \& Shamire, 1993, qtd by Turner \& Haslam, 2001) Therefore, prototypical leaders working against bias should have a positive impact on self-concept and reduce organizational interpersonal uncertainty for employees opposed to bias and employees feeling discrimination as a result of bias. Additionally, such leaders could discourage or make self-aware potential perpetrators of bias behavior. Lastly, the relationship between higher rank and intervening suggests the possibility of future research in conjunction with our finding that women underrepresentation in colleges is associated with less witnessing and intervention. Specifically, where the percentage of women in colleges is below the institutional average, does rank and other intersectional characteristics (e.g., gender, race/ethnicity, sexual orientation) of underrepresented faculty members influence how often they witness and intervene in situations of bias?

Our bivariate results suggest that individuals are less likely to intervene when they perceive their colleagues as likely to do so, reflecting the classic "bystander effect" (Latane \& Darley, 1970). That is, faculty who perceive that their colleagues are likely to intervene may experience diffusion of responsibility rather than assuming responsibility - the sense that others are going to act so “I don’t have to.” This reminds us that attempts to change departmental norms are complicated and might not always lead to more intervention. This variable fell just short of attaining statistical significance in the multivariate model $(p=.053)$, suggesting that once we control for other variables of theoretical import, perceptions that colleagues will intervene have a weaker impact on one's own intention to intervene. 
Levine et al. (2010) find that group size and bystander gender influence intervention when women are subjected to male bias. Levine and Crowther (2008) in a simulated "real world" experiment of male-on-female aggressive behavior find that "[i]t is only when the [gender] identity of bystanders and victim is consonant that the solidarity provided by increased group size contributes towards greater attempts to help an in-group victim in need.” Their results showed that a woman helping another woman is inhibited only when in a group with men, and that a man helping a woman is inhibited by the presence of other men. Additionally, they find that groups of entirely women intervened and that when a man was in a group of women he was likely to intervene. Future research on bystander intervention in the academic workplace is needed to expand upon the present study and past SCT findings controlling for group size and the social statuses composing bystander groups.

Bias awareness training had a significant effect on the extent to which respondents report having witnessed bias incidents. While it is important to raise bias awareness because recognizing bias is a precursor to being able to intervene, the results of the present and past studies (Ashburn-Nardo et al., 2014) also point to the need for training to focus on riskappropriate intervention strategies and increasing individuals’ confidence in their ability to intervene on behalf of the targets of bias in the workplace. Past SCT research (Hogg \& Terry, 2000; Levine et al. 2005; Mummendey \& Wenzel, 1999) suggests that bias intervention trainings have the potential to encourage inclusivity for underrepresented group in the academic workplace. Trainings highlighting the situational discrimination faced by underrepresented groups potentially activate for attendees the salience of perpetrator, victim, and bystander groups during biased situations. Trainings that highlight the "salience of relevant intergroup comparative context” potentially change “contextual self-categorization and, therefore, people's internalized 
attitudes and behaviors.” (Hogg \& Terry, 2000, p. 125) Our preliminary findings on bystander intervention trainings suggest that rendering visible bias could promote bystander intervention. Research by Levine et al. (2005) which focuses on promoting bystander intervention during situations of bias suggests that self-concept dynamically responds to changes in the social context, which triggers self-categorization change. Their goal and ours is to shift group characterizations from subordinate to superordinate in order to promote bias reduction and inclusivity.

\section{Limitations}

Our study has several limitations, including the potential impact of common method bias (Doty \& Glick, 1998). Our data is derived using one survey instrument and self-report. While there is a risk that this could increase the correlation among our variables, Meade, Watson, and Kroustalis (2007) found that the magnitude of such an increase is often minor. Second, while it demonstrated good reliability, our measure of bias incidents captures only a few of the full range of possible bias incidents that may occur in the academic workplace. Qualitative studies of faculty could be a next step in better describing the full array of bias incidents that faculty witness. From those, a longer, more detailed inventory of bias incidents could be used to survey respondents. Our measure of bystander intervention is limited by a binary view of the concept: did people intervene (or not), and would they expect their colleagues to intervene (or not) in various situations? This operationalization does not reflect the reality that there are many ways to intervene, each associated with its own degree and type of risk. Research is needed to develop a comprehensive taxonomy of intervention behaviors in the context of workplace bias incidents from which to develop training materials. This would go a long way toward reducing bias in the workplace. Finally, given the demographics of the campus on which the study was done, the 
sample is predominantly white and thus not representative of faculty nationally. Further research with more diverse and intersectional samples of faculty is needed.

\section{Conclusion}

In both research and campus practices, growing attention is being paid to improving workplace climate for underrepresented faculty members. The results of this study suggest that aspects of bystander intervention may be helpful in improving academic workplace climate and serve as an important leverage point for creating change. Utilizing self-categorization theory, the current study also shows that engaging in bystander action to thwart bias behavior in their departments may be easier for those with greater status (tenured faculty members). Bystander intervention may be more challenging for those who feel more connected to their department communities and thus may fear the social capital costs of stepping in. This suggests that when developing more specific bystander-focused training to promote bystander intervention with specialized skill building, it may be useful to start by engaging department members with greater power as “early adopters” (Rogers, 2003) who might then become leaders in promoting bystander action to address bias. As campuses work to recruit and retain a more diverse faculty in disciplines where they are underrepresented (e.g., women in Business and in Science, Technology, Engineering and Mathematics (STEM) through initiatives like the National Science Foundation's ADVANCE grants), attention to understanding and developing bystander-focused training may be an important innovation. 


\section{References}

Acker, J. (2012). Gendered organizations and intersectionality: Problems and possibilities. Equality, Diversity and Inclusion: An International Journal, 31(3), 214-224.

Antecol, H., \& Cobb-Clark, D. (2003). Does sexual harassment training change attitudes? A view from the federal government. Social Science Quarterly, 84(4), 826-842.

Ashburn-Nardo, L., Blanchar, J. C., Petersson, J., Morris, K. A., \& Goodwin, S. A. (2014). Do you say something when it's your boss? The role of perpetrator power in prejudice confrontation. Journal of Social Issues, 70(4), 615-636.

Ashburn-Nardo, L., Morris, K.A., \& Goodwin, S.A. (2008). The Confronting Prejudiced Responses (CPR) model: Applying CPR in organizations. Academy of Management Learning \& Education, 7(3), 332-342.

August, L., \& Waltman, J. (2004). Culture, climate, and contribution: Career satisfaction among female faculty. Research in Higher Education, 45(2), 177-192.

Banyard, V.L. (2011). Who will help prevent sexual violence: Creating an ecological model of bystander intervention. Psychology of Violence, 1(3), 216-229.

Banyard, V.L. (2015). Toward the next generation of bystander prevention of sexual and relationship violence: Action coils to engage communities. New York, NY: Springer.

Banyard, V.L., Moynihan, M.M., Cares, A.C., \& Warner, R. (2014). How do we know if it works? Measuring outcomes in bystander-focused abuse prevention on campuses. Psychology of Violence, 4(1), 101-115.

Basford, T.E., Offermann, L.R., \& Behrend, T.S. (2014). Do you see what I see? Perceptions of gender microaggressions in the workplace. Psychology of Women Quarterly, 38(3), 340349. 
Becker, J.C., \& Barreto, M. (2014). Ways to go: Men’s and women’s support for aggressive and nonaggressive confrontation of sexism as a function of gender identification. Journal of Social Issues, 70(4), 668-686.

Becker, J.C., Zawadzki, M.J., \& Shields, S.A. (2014). Confronting and reducing sexism: A call for research on intervention. Journal of Social Issues, 70(4), 603-614.

Bickman, L. (1972). Social influence and diffusion of responsibility in an emergency. Journal of Experimental Social Psychology, 8(5), 438-445.

Biggane, J.E., Allen, D.G., \& Albert, L.S. (2016). The role of positive illusions in employment relationships. Human Resource Management Review, 26(3), 270-281.

Bowes-Sperry, L., \& O’Leary-Kelly, A.M. (2005). To act or not to act: The dilemma faced by sexual harassment observers. Academy of Management Review, 30(2), 288-306.

Brinkman, B. G., Dean, A. M., Simpson, C. K., McGinley, M., \& Rosén, L. A. (2015). Bystander intervention during college women’s experiences of gender prejudice. Sex Roles, 72, 485-498.

Brown, A. L., Banyard, V. L., \& Moynihan, M. M. (2014). College students as helpful bystanders against sexual violence gender, race, and year in college moderate the impact of perceived peer norms. Psychology of Women Quarterly, 38(3), 350-362.

Buchanan, N.T., Settles, I.H., Hall, A.T., \& O’Connor, R.C. (2014). A review of organizational strategies for reducing sexual harassment: Insights from the U.S. Military. Journal of Social Issues, 70(4), 687-702.

Carnes, M., Devine, P.G., Isaac, C., Manwell, L.B., Ford, C.E., Byars-Winston, A., Fine, E., \& Sheridan, J. (2012). Promoting institutional change through bias literacy. Journal of Diversity in Higher Education, 5(2), 63-77. 
Collins, P. H. (1998). It's all in the family: Intersections of gender, race, and nation. Hypatia, 13(3), 62-82.

Crenshaw, K. (1991). Mapping the margins: Identity politics, intersectionality, and violence against women. Stanford Law Review, 43(6), 1241-1299.

Doty, D.H., \& Glick, W.H. (1998). Common method bias: Does common methods variance really bias results? Organizational Research Methods, 1(4), 374-406.

Eliezer, D., \& Major, B. (2011). It’s not your fault: The social costs of claiming discrimination on behalf of someone else. Group Processes \& Intergroup Relations, 15(4), 487-502.

Good, J.J., Moss-Racusin, C.A., \& Sanchez, D.T. (2012). When do we confront? Perceptions of costs and benefits predict confronting discrimination on behalf of others. Psychology of Women Quarterly, 36(2), 210-226.

Harvey, M., Treadway, D., \& Heames. J.T. (2007). The occurrence of bullying in global organizations: A model and issues associated with social/emotional contagion. Journal of Applied Social Psychology, 37(11), 2576-2599.

Hart, J. (2016). Dissecting a gendered organization: Implications for career trajectories for midcareer faculty women in STEM. The Journal of Higher Education, 87(5), 605-634.

Hogg, M. A. (2001). A social identity theory of leadership. Personality and social psychology review, 5(3), 184-200.

Hogg, M.A., \& Terry, D.J. (2000). Social identity and self-categorization processes in organizational contexts. Academy of Management Review, 25, 121-140.

House, R.J., \& Shamir, B. (1993). Toward the integration of transformational, charismatic, and visionary theories. In M.M. Chemers \& R. Ayman (Eds.), Leadership theory and research: Perspectives and directions (pp. 81-107). San Diego, CA: Academic Press. 
Hughes, C.C., Schilt, K., Gorman, B.K., \& Bratter, J.L. (2017). Framing the faculty gender gap: A view from STEM doctoral students. Gender, Work, and Organizations, 24(4), 399-416.

Inman, M. \& Baron, R. (1996). Influence of prototypes on perceptions of prejudice. Journal of Personality and Social Psychology, 70(4), 727-39.

Jackson, S.M., Hillard, A.L., \& Schneider, T.R. (2014). Using implicit bias training to improve attitudes toward women in STEM. Social Psychology Education, 17, 419-438.

Latane, B., \& Darley, J.M. (1968). Bystander intervention in emergencies: Diffusion of responsibility. Journal of Personality and Social Psychology, 8(4, Pt. 1), 377-383.

Latane, B., \& Darley, J.M. (1970). The unresponsive bystander: Why doesn't he help? New York, NY: Appleton-Century-Crofts.

Lee, R.T., \& Brotheridge, C.M. (2011). Sex and position status differences in workplace aggression. Journal of Managerial Psychology, 26(5), 403-418.

Lester, J., Sallee, M., \& Hart, J. (2017). Beyond gendered universities? Implications for research on gender in organizations. NASPA Journal About Women in Higher Education, 10(1), 126.

Levine, M., \& Cassidy, C. (2009). Groups, identities, and bystander behavior. In S. Stürmer \& M. Snyder (Eds.), The psychology of prosocial behavior: Group processes, intergroup relations, and helping (209). Hoboken, NJ: Wiley-Blackwell.

Levine, M., Cassidy, C., Brazier, G., \& Reicher, S. (2002). Self-categorization and bystander non-intervention: Two experimental studies. Journal of Applied Social Psychology, 32(7), 1452-1463.

Levine, M., Cassidy, C., \& Jentzsch, I. (2010). The implicit identity effect: Identity primes, group size, and helping. British Journal of Social Psychology, 49(4), 785-802. 
Levine, M., \& Crowther, S. (2008). The responsive bystander: How social group membership and group size can encourage as well as inhibit bystander intervention. Journal of Personality and Social Psychology, 95(6), 1429.

Levine, M., Prosser, A., Evans, D., \& Reicher, S. (2005). Identity and emergency intervention: How social group membership and inclusiveness of group boundaries shape helping behavior. Personality and Social Psychology Bulletin, 31(4), 443-453.

Low, K.S.D., Radhakrishnan, P., Schneider, K.T., \& Rounds, J. (2007). The experiences of bystanders of workplace ethnic harassment. Journal of Applied Social Psychology, 37, 2261-2297.

Maranto, C.L., \& Griffin, A.E.C. (2011). The antecedents of a 'chilly climate’ for women faculty in higher education. Human Relations, 64(2), 139-159.

McMahon, S., Palmer, J.E., Banyard, V.L., Murphy, M., \& Gidycz, C.A. (2015). Measuring bystander behavior in the context of sexual violence prevention: Lessons learned and new directions. Journal of Interpersonal Violence, July 5.

Meade, A., Watson, A., \& Kroustalis, C. (2007, April). Assessing common methods bias in organizational research. Paper presented at the $22^{\text {nd }}$ Annual Meeting of the Society for Industrial and Organizational Psychology, New York, NY.

Miner-Rubino, K., \& Cortina, L.M. (2004). Working in a context of hostility toward women: Implications for employees’ well-being. Journal of Occupational Health Psychology, 9, 107-122.

Mummendey, A., \& Wenzel, M. (1999). Social discrimination and tolerance in intergroup relations: Reactions to intergroup difference. Personality and Social Psychology Review, 3(2), 158-174. 
Nielsen, M.B., \& Einarsen, S. (2012). Outcomes of exposure to workplace bullying: A metaanalytic review. Work \& Stress, 26(4), 309-332.

Nunnally, J. C. (1978). Psychometric Theory (2nd ed.). New York: McGraw-Hill

Rogers, E.M. (2003). Diffusion of innovations (5 ${ }^{\text {th }}$ ed.). New York, NY: Simon and Schuster.

Rotundo, M., Nguyen, D.H., \& Sackett, P.R. (2001). A meta-analytic review of gender differences in perceptions of sexual harassment. Journal of Applied Psychology, 86(5), 914-922.

Samnani, A-K. (2013). 'Is this bullying?’: Understanding target and witness reactions. Journal of Managerial Psychology, 28(3), 290-305.

Schmidt, M.T., Branscombe, N.R., Kobrynowicz, D. \& Owen, S. (2002). Perceiving discrimination against one’s gender group has different implications for well-being in women and men. Personality and Social Psychology Bulletin, 28(2), 197-210.

Settles, I.H., Cortina, L.M., Buchanan, N.T., \& Miner, K.N. (2012). Derogation, discrimination, and (dis)satisfaction with jobs in science: A gendered analysis. Psychology of Women Quarterly, 37(2), 179-191.

Shea, C.M., Malone, M.F.T., Young, J.R., \& Graham, K.J. (under review). Interactive theater: An effective tool to reduce gender bias in faculty searches.

Shea, C.M., Young, J.R., Malone, M.F.T., Graham, K.J., \& Banyard, V. (under review). Faculty colleague intervention: Mitigating the negative impact of bias on academic workplace climate.

Shelton, J. N., \& Stewart, R. E. (2004). Confronting perpetrators of prejudice: The inhibitory effects of social costs. Psychology of Women Quarterly, 28, 215-223.

Shields, S. A. (2008). Gender: An intersectionality perspective. Sex roles, 59(5-6), 301-311. 
Swim, J.K., \& Hyers, L.L. (2009). Sexism. In T.D. Nelson (Ed.), Handbook of prejudice, stereotyping, and discrimination (pp. 407-430). New York, NY: Psychology Press.

Turner, J. C., \& Haslam, S. A. (2001). Social identity, organizations, and leadership. Groups at work: Theory and research, 25-65.

Turner, J. C., Hogg, M. A., Oakes, P. J., Reicher, S. D., \& Wetherell, M. S.(1987). Rediscovering the social group: A self-categorization theory. Basil Blackwell.

Ullrich, J., Christ, O., \& Schlüter, E. (2006). Merging on Mayday: Subgroup and superordinate identification as joint moderators of threat effects in the context of European Union's expansion. European Journal of Social Psychology, 36(6), 857-876.

van Knippenberg, D., van Knippenberg, B., \& van Dijk, E. (2000). Who takes the lead in risky decision making? Effects of group members' risk preferences and prototypicality. Organizational Behavior and Human Decision Processes, 83(2), 213234.

Vartia, M. (2001). Consequences of workplace bullying with respect to the well-being of its targets and the observers of bullying. Scandinavian Journal of Work Environment Health, 27(1), 63-69.

Virginia Institute of Technology (2008). 2008 Faculty work-life survey. Retrieved from http://www.portal.advance.vt.edu/index.php/tags/climate-survey

Wenzel, M., Mummendey, A., \& Waldzus, S. (2007). Superordinate identities and intergroup conflict: The ingroup projection model. European Review of Social Psychology, 18(1), 331-372. 


\section{ABOUT THE AUTHORS}

Dr. Christine Shea, Professor of Technology and Operations Management, joined the UNH ADVANCE leadership team in 2008. Her current research is on how colleague intervention can reduce the negative impact of bias incidents in the academic workplace. In addition to her faculty appointment, she has held the positions of Interim Vice Provost for Faculty Development and Inclusive Excellence and Associate Dean of Graduate Programs and Research in the college of business. Prior to earning her PhD from the University of Western Ontario, she worked for ten years and held various project and operations management positions in the aerospace industry.

Justin Young is a Senior Institutional Research and Planning Analyst for the University of Maine System. He obtained his doctorate in Sociology from the University of New Hampshire in 2015, where much of his research focused on issues of racial/ethnic diversity and inequality in social networks, neighborhoods, and labor markets. Young also served as a Postdoctoral Researcher for UNH's ADVANCE Program and, prior to completing his graduate work, was a Research Assistant for UNH’s Carsey School of Public Policy.

Victoria Banyard, Ph.D. is a Professor in the Department of Psychology at the University of New Hampshire and a member of the Prevention Innovations Research Center. Her over two decades of research has focused on understanding the effects and prevention of interpersonal violence, including harassment in educational and employment contexts. She has specifically focused on understanding what motivates third parties to risky situations (bystanders or actionists) to step in and help others and reduce risk for negative behaviors. She has published numerous peer review articles on these topics and is the author of Toward the Next Generation of Bystander Prevention of Sexual and Relationship Violence.

Mary Fran T. Malone is an associate professor and chair of the department of political science at the University of New Hampshire. Her research focuses on political attitudes and behaviors in Latin America, particularly citizen support for the rule of law, political institutions, and democratic governance. Prof. Malone is currently working on a monograph that examines how democracies can build police forces that fight crime while also protecting the civil liberties and rights of the citizens they serve.

Dr. Karen Graham is a Professor and Chair of the Department of Mathematics and Statistics at the University of New Hampshire. She has been a member of the UNH ADVANCE leadership team since 2008 and currently serves as the program's Executive Director. Her research focuses on the teaching and learning of mathematics and mathematics teacher development. In addition to her faculty position, she served as the inaugural director of the Joan and James Leitzel Center for Mathematics, Science, and Engineering Education from 2002 - 2012 and on the board of the National Council of Teachers of Mathematics from 2013-2015.

Gerard “Jay” Byron, Ph.D. is a Postdoctoral Researcher with UNH ADVANCE. His current research focuses on identity, the disclosure of sexual orientation, and social groups. He earned his doctorate in Sociology at the University of Massachusetts Boston in 2017. Here his research focused on identity, the expectations to attain social roles (e.g., worker, spouse, parent), and psychological distress. Prior to his Ph.D., he worked as a Research Coordinator II in the 
Psychiatry Department at the University of Massachusetts Medical School. Here he studied the delivery of patient care. 